\title{
Motor Evoked Potentials of the Upper Extremities in Healthy Children
}

\author{
Soon-Won Yook, M.D., Sung-Hee Park, M.D., Myoung-Hwan Ko, M.D., Jeong-Hwan Seo, M.D.
}

\begin{abstract}
Department of Physical Medicine and Rehabilitation, Institute for Medical Sciences, Chonbuk National University Medical School, Research Institute of Clinical Medicine, Chonbuk National University Hospital, Jeonju 561-180, Korea
\end{abstract}

\begin{abstract}
Objective To evaluate and compare the organization of descending motor pathways to upper extremity muscles among healthy children.

Method The healthy children were 16 males and 7 females aged 1-19 years (average, 9 years), and eight healthy adults were enrolled as the control group. Transcranial magnetic stimulation was applied to bilateral motor cortices, and motor evoked potentials (MEPs) were recorded using surface electrodes from the first dorsal interossei (FDI), the biceps brachii (BIC), and the deltoid (DEL) muscles. The onset latency, central motor conduction time (CMCT), and amplitude were obtained during a relaxed state.

Results MEPs of FDI were obtained from subjects aged 13 months. The frequency of obtaining MEPs in proximal and distal muscles increased with age, although there was a less frequent incidence of obtaining MEPs in the proximal BIC and DEL muscles compared with those in the distal FDI muscle. MEP amplitudes increased with age, whereas latencies were relatively constant. CMCTs showed a similar pattern of maturation, and adult values were obtained by 13-years-of-age.

Conclusion These results suggest that the proximal and distal muscles of the upper extremities show different maturation and organization patterns.
\end{abstract}

Key Words Motor evoked potential, Upper extremity, Proximal and distal muscle, Brain maturation

\section{INTRODUCTION}

Motor evoked potential (MEP) studies of the intrinsic hand muscles using transcranial magnetic stimulation

Received October 20, 2010; Accepted June 28, 2011

Corresponding author: Sung-Hee Park

Department of Physical Medicine and Rehabilitation, Chonbuk National University Medical School, San 2-20, Keumam-dong, Dukjin-gu, Jeonju 561-180, Korea

Tel: +82-63-250-1810, Fax: +82-63-254-4145, E-mail: shpark0130@jbnu. ac.kr

(ㄷ) This is an open-access article distributed under the terms of the Creative Commons Attribution Non-Commercial License (http:// creativecommons.org/licenses/by-nc/3.0) which permits unrestricted noncommercial use, distribution, and reproduction in any medium, provided the original work is properly cited.

Copyright $\odot 2011$ by Korean Academy of Rehabilitation Medicine
(TMS) is the gold standard method for evaluating integrity of the corticospinal tract and estimating prognosis of central nervous system (CNS) disorders in adult patients. ${ }^{1,2}$

In Korea, numerous studies have been conducted using MEP in adult patients with CNS disorders, but, surprisingly, MEP studies of pediatric subjects are extremely rare, ${ }^{3,4}$ which is in contrast to those conducted outside of Korea. ${ }^{5,6}$ Furthermore, even outside of Korea, few studies have investigated the maturation and organization of the proximal and distal upper extremity muscles using TMS in adult subjects ${ }^{7}$ and, to our knowledge, no studies have investigated the proximal 
and distal muscles of the upper extremities in pediatric subjects. The safety of TMS has been established in human and animal models. ${ }^{8-10}$ Until recently, there has been no report on serious adverse events in children who have received single-pulse TMS. TMS-related neurocardiogenic syncope has been reported in children; ${ }^{11}$ however, this adverse event can be prevented by implementing preventative measures. ${ }^{12}$

This study evaluated the age-related changes in the corticospinal neurophysiology of the proximal and distal upper extremity muscles in healthy children and demonstrated differences in the maturational changes of this motor pathway for each muscle.

\section{MATERIALS AND METHODS}

\section{Subjects}

Twenty-three healthy children and eight healthy adults in their 20s were enrolled. The subjects were chosen by the method suggested by Müller et al. ${ }^{13}$ All children > 6 -years-of-age and their parents were fully informed about the study protocol and gave their consent before measurements. The trial was performed under the approval of the institutional review board for clinical studies.

Healthy children were aged $9.1 \pm 5.0$ years (range, 1-19 years) and included 16 males and seven females. The healthy adults were 27.4 \pm 1.4 years (range, 2629 years) and included six males and two females. In previous studies investigating developmental changes in corticospinal neurophysiology using TMS, MEP at rest was not evoked in children aged $\leq 5$ years, and resting central motor conduction time was assessed by measuring the latency of MEP in 13-year-old children. ${ }^{3,12-14}$ Based on these findings, the subjects were divided into three groups according to their age: group $A$, children $\leq 5$ years $(n ; 6)$; group $B$, children 6 - 12 years $(\mathrm{n}=10)$; and group $\mathrm{C}$, children $\geq 13$ years $(\mathrm{n}=7)$ (Fig. 1 ).

\section{Methods}

The Medtronic Keypoint ${ }^{\circledR}$ (Medtronic Inc., Skovlunde, Denmark) was used as an electrodiagnostic device. The sensitivity was adjusted to range from $50 \mu \mathrm{V}-1 \mathrm{mV}$ per division. The filter setting was $2-2,000 \mathrm{~Hz}$, and the sweep rate was $50 \mathrm{~ms}$. The subjects were tested with their eyes open in a relaxed supine position. We did not use the facilitation method even if we could not observe the evoked potential. Electromyographic activity was recorded from both sides with surface electrodes. MEPs were examined in the first dorsal interossei (FDI), the biceps brachii (BIC), and the deltoid (DEL) muscles. We attached active electrodes on the belly of each muscle. Reference electrodes were placed at a distance of at least $1 \mathrm{~cm}$ from the active electrode. The ground electrode was placed on the sternum. We applied TMS to each cerebral hemisphere in turn.

TMS was performed with a Medtronic Magpro ${ }^{\circledR}$ (Medtronic Inc., Skovlunde, Denmark) stimulator with a diameter of $70 \mathrm{~mm}$ and a butterfly-shaped coil on the right and left optimal stimulus positions. The coil was held tangential to the scalp, with the handle angled backwards and $45^{\circ}$ away from the midline. The stimulated scalp sites were identified using a fitting cap, pre-marked with sites at an $1 \mathrm{~cm}$ spacing in the latitude-longitude coordinate system. The inter-stimulus interval was a minimum of 10 seconds. We maintained coil temperature to not exceed $35^{\circ} \mathrm{C}$. The threshold was defined as the minimum stimulation intensity required to evoke a peak-to-peak amplitude of $>50 \mu \mathrm{V}$ in at least five of ten consecutive trials. The threshold was determined using $5 \%$ increases of stimulator output from $30 \%$ maximal stimulus intensity. The latency and the amplitude were gathered by averaging the values from four stimuli at $110 \%$ of threshold.

The MEP frequency was defined as the number of subjects undergoing MEP analysis divided by the total subjects on trial. To evaluate the central motor conduction time (CMCT) of the FDI, the cervical spine

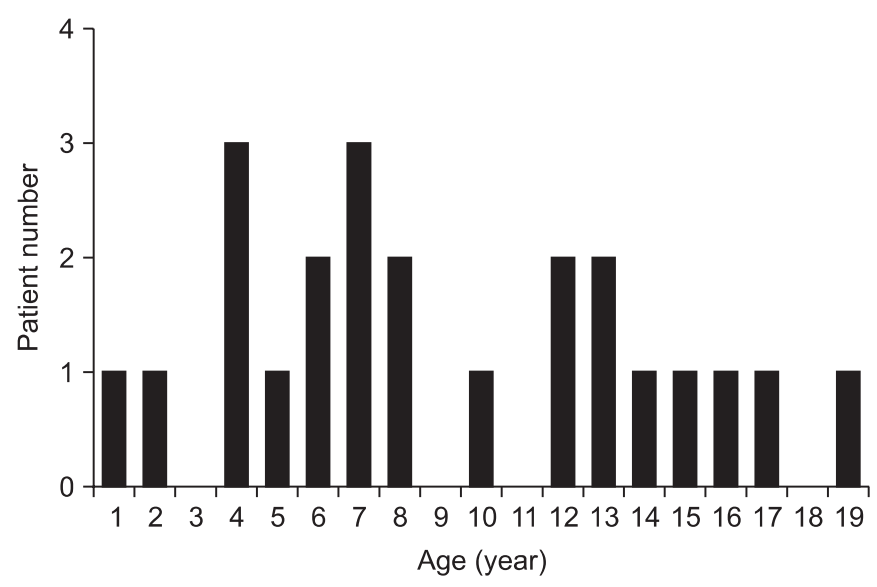

Fig. 1. Demographics of the 23 healthy children. 
Table 1. Number of Subjects with Motor Evoked Potentials

\begin{tabular}{ccccc}
\hline Recording site & Group (age) & $\begin{array}{c}\text { Number of subjects with MEP/ } \\
\text { total subjects (\%) }\end{array}$ & $\chi^{2}$ & sig. \\
\hline FDI & A (1-5) & $6 / 6(100 \%)$ & & \\
& B (6-12) & $10 / 10(100 \%)$ & & \\
& C ( $\geq 13)$ & $7 / 7(100 \%)$ & & \\
BIC & Adults & $8 / 8(100 \%)$ & 1.571 & 0.242 \\
& A (1-5) & $3 / 6(50 \%)$ & 0.168 & \\
\hline DEL & B (6-12) & $8 / 10(80 \%)$ & & 0.182 \\
& C ( $\geq 13)$ & $5 / 7(71 \%)$ & & 0.268 \\
\hline
\end{tabular}

FDI: First dorsal interossei, BIC: Biceps brachii, DEL: Deltoid, sig.< 0.05: Significantly increased or decreased compared to previous age group

was magnetically stimulated using a $140 \mathrm{~mm}$ diameter, round coil with the same stimulator used for transcranial stimulation. Stimulation was performed until we identified the maximal FDI response. The CMCT was defined as the differences between the MEP latency for FDI while stimulating the motor cortex and the cervical spine.

\section{Statistics}

SPSS version 13.0 for Windows (SPSS Inc., Chicago, USA) was used for the statistical analysis. We used the chisquare test to compare the frequency of induced MEPs by age in each muscle. We used the Wilcoxon signedrank test to compare the latency, CMCT, amplitude, and the frequency of obtaining MEPs among each muscle. A $\mathrm{p}<0.05$ was considered statistically significant.

\section{RESULTS}

MEP frequency and parameters in healthy children MEP frequency: MEPs were recorded from the FDI in all 23 healthy children aged 13 months-19 years. MEPs were evoked in $16(70 \%)$ and $12(52 \%)$ of the 23 subjects on the BIC and DEL, respectively. The MEPs of the BIC and DEL were less frequently observed that those of the FDI.

The frequency of MEPs for the BIC and DEL was higher in groups B and C than that in group A. However, MEPs for the BIC and DEL tended to be less frequently observed
Table 2. Latency of Motor Evoked Potentials

\begin{tabular}{cll}
\hline Recording site & Group (age) & Latency (ms) \\
\hline FDI & A $(1-5)$ & $21.6 \pm 3.5(\mathrm{n} ; 6)$ \\
& B $(6-12)$ & $19.8 \pm 3.4(\mathrm{n} ; 10)$ \\
& C $(\geq 13)$ & $20.9 \pm 1.1(\mathrm{n} ; 7)$ \\
& $1-19$ & $20.6 \pm 2.9(\mathrm{n} ; 23)$ \\
& Adults & $20.9 \pm 0.8(\mathrm{n} ; 8)$ \\
BIC & A $(1-5)$ & $12.0 \pm 1.7(\mathrm{n} ; 3)$ \\
& B (6-12) & $13.0 \pm 2.9(\mathrm{n} ; 8)$ \\
& C ( $\geq 13)$ & $12.1 \pm 1.9(\mathrm{n} ; 5)$ \\
& $1-19$ & $14.0 \pm 4.7(\mathrm{n} ; 16)$ \\
& Adults & $13.8 \pm 0.7(\mathrm{n} ; 8)$ \\
DEL & A $(1-5)$ & $12.9 \pm 0.9(\mathrm{n} ; 2)$ \\
& B (6-12) & $13.3 \pm 1.6(\mathrm{n} ; 7)$ \\
& C ( $\geq 13)$ & $13.4 \pm 1.0(\mathrm{n} ; 3)$ \\
& $1-19$ & $14.0 \pm 2.8(\mathrm{n} ; 12)$ \\
& Adults & $14.4 \pm 0.9(\mathrm{n} ; 8)$ \\
\hline
\end{tabular}

FDI: First dorsal interossei, BIC: Biceps brachii, DEL: Deltoid

in group C compared with those in group B. MEPs were obtained for all examined muscles in all subjects in the adult group (Table 1).

MEP parameters: MEP latency did not show significant differences according to age in each of the examined muscles (Table 2).

When we compared the CMCT of the children 1-12- 
years-of-age, with the CMCT of those $>12$ years and normal adults in their 20s, children $>12$ years showed a statistically significant decrease in the CMCT compared to that in the other groups $(\mathrm{p}<0.05)$. The CMCT of children $>12$ years and that of normal adults aged in their 20s was not statistically different (Table 3 ).

MEP amplitude increased significantly with age for the FDI $(p<0.05)$. MEP amplitude of the BIC and DEL tended to increase with age. A significant increase in group $B$ compared with that in group A was observed for the MEP amplitude of the BIC. A significant increase in the MEP amplitude of the DEL muscles was observed in group C compared with that in group B.

These results showed that MEP amplitude increased at an early age in the BIC rather than that in the DEL $(p<0.05)$. Additionally, the MEP amplitudes of all examined muscles increased significantly in group C

Table 3. CMCT of the First Dorsal Interossei Muscle

\begin{tabular}{cc}
\hline Age (years) & CMCT $(\mathbf{m s})$ \\
\hline$\leq 12$ & $10.4 \pm 4.0$ \\
$\geq 13$ & $7.8 \pm 0.9$ \\
$1-19$ & $9.6 \pm 3.5$ \\
Adult & $7.6 \pm 0.9$ \\
\hline
\end{tabular}

CMCT: Central motor conduction time compared to those in group A $(\mathrm{p}<0.05)$ (Table 4).

\section{Adverse effect of TMS}

Known adverse events following TMS such as syncope, seizure, headache, hearing problems, or changes in emotion were not observed in this study. ${ }^{15}$

\section{DISCUSSION}

MEPs of the FDI were observed in a 13-month-old subject at rest. The age of this child was younger than that reported in earlier studies. Previous studies demonstrated that MEPs are observed in relaxed abductor digiti minimi of children $>8$ years by Koh and Eyre ${ }^{14}$ and in a relaxed FDI of a 2-year-old child by Nezu et al. ${ }^{4}$

In every age group, a less frequent incidence of obtaining MEPs in the BIC, DEL, and the proximal muscle group was observed, compared to that in the FDI, a distal muscle group. In distal muscles of the upper extremities (e.g., FDI), MEPs were observed in every age group beginning at 13 months. However, in contrast with the MEP response evoked in distal muscle, MEPs were not elicited in proximal muscles of the upper extremities (BIC and DEL) under maximal stimulation intensity in some children aged $\geq 12$ years. The oldest age of a subject with no MEP was 16 years. But, MEPs were observed in

Table 4. Amplitude of Motor Evoked Potentials

\begin{tabular}{|c|c|c|c|}
\hline Recording site & Age (years) & Amplitude $(\mu \mathrm{V})$ & $\mathbf{p}$ \\
\hline \multirow[t]{5}{*}{ FDI } & A (1-5) & $419.4 \pm 348.9(\mathrm{n} ; 6)$ & \\
\hline & B (6-12) & $1,071.9 \pm 585.4(\mathrm{n} ; 10)$ & $0.002^{*}$ (compared to $1-5$ years) \\
\hline & $C(\geq 13)$ & $2,363.1 \pm 1,238.2(n ; 7)$ & $0.003^{*}$ (compared to $6-12$ years) \\
\hline & $1-19$ & $1,314.4 \pm 1,098.3(n ; 23)$ & \\
\hline & Adults & $3,443.8 \pm 1,190.5(\mathrm{n} ; 8)$ & $<0.001^{*}$ (compared to $1-19$ years) \\
\hline \multirow[t]{5}{*}{ BIC } & $A(1-5)$ & $332.8 \pm 122.3(\mathrm{n} ; 3)$ & \\
\hline & B (6-12) & $692.3 \pm 477.4(\mathrm{n} ; 8)$ & 0.07 (compared to $1-5$ years) \\
\hline & $C(\geq 13)$ & $1,552.1 \pm 1,473.7(\mathrm{n} ; 5)$ & 0.16 (compared to $6-12$ years) \\
\hline & $1-19$ & $559.1 \pm 406.0(\mathrm{n} ; 16)$ & \\
\hline & Adults & $1,977.2 \pm 927.2(\mathrm{n} ; 8)$ & $>0.05$ (compared to $1-19$ years) \\
\hline \multirow[t]{5}{*}{ DEL } & $A(1-5)$ & $327.0 \pm 98.8(\mathrm{n} ; 2)$ & \\
\hline & B (6-12) & $600.5 \pm 298.8(\mathrm{n} ; 7)$ & 0.17 (compared to $1-5$ years) \\
\hline & $C(\geq 13)$ & $1,535.7 \pm 646.2(\mathrm{n} ; 3)$ & $0.01^{*}$ (compared to $6-12$ years) \\
\hline & $1-19$ & $585.4 \pm 371.9(\mathrm{n} ; 12)$ & \\
\hline & Adults & $1,767.6 \pm 647.3(\mathrm{n} ; 8)$ & $>0.05$ (compared to $1-19$ years) \\
\hline
\end{tabular}

FDI: First dorsal interossei, BIC: Biceps brachii, DEL: Deltoid ${ }^{*} \mathrm{p}<0.05$ 
proximal and distal muscles of the upper extremities in all subjects in the control group who were in their late 20s. This observation implies a difference between distal and proximal upper extremity motor neuron organization.

The lower frequency of obtaining MEPs in proximal muscle than distal muscle in healthy children was thought to be due to late maturation of the corticospinal tract to proximal muscles or a higher cortical excitatory threshold resulting in lower excitability. ${ }^{16,17}$

The frequency of obtaining MEPs in the proximal muscles (BIC and DEL) of children $>5$-years-ofage showed an increasing trend compared to that between children 1-5 years. However, the frequency of obtaining MEPs from the BIC and DEL decreased in children >12-years-of-age compared to that in children 6-12-years-of-age. These findings were also thought to be the result of corticospinal tract maturation and myelination in the upper extremity proximal muscles with aging, ${ }^{14,18}$ but individual differences in corticospinal tract maturation pattern can exist in distal muscles.

In this study, the CMCT of healthy children $>12$ years showed a statistically relevant decrease compared to that in healthy children aged 1-12 years. But no statistical difference in healthy adults was observed, which corresponded with Nezu et al. ${ }^{3}$ who stated that all MEP parameters reach adult levels at the age of 13 . Therefore, the CMCT may be useful for investigating maturation in the descending motor pathways or the differences between motor pathways of each muscle group in healthy children.

Müller et al. ${ }^{19}$ reported that central motor conduction velocity increases as children get older and reaches healthy adult levels by the age of 11 . In this study, a statistically relevant decrease in onset latency was not observed, which may have been due to influences of increasing nerve conduction velocity, as maturation of synapses and decreasing nerve conduction time with distance increases as children grow taller. Further studies are needed to clarify the relationship between height and the CMCT.

Although Rothwell et al. ${ }^{20}$ reported using TMS-MEP clinically was hard due to amplitude variability, we observed an increase in MEP amplitude as children aged, suggesting that the MEP amplitude reflects corticospinal tract maturation and muscle growth as children get older.
The distal muscle (FDI) showed a statistically relevant amplitude increase at an earlier age than that of the proximal muscles (BIC and DEL) and continuously showed relevant amplitude increases. A statistically relevant increase in amplitude was observed in the BIC of group B and in the DEL of group C, suggesting that the proximal and distal muscles have a different neuronal circuit. ${ }^{21}$ It also suggests that each muscle can have a different maturation pattern even within the same proximal muscle group. Therefore, a TMS-MEP study of the upper extremities should be conducted in proximal muscles as well as distal muscles, and additional TMSMEP studies of each muscle should be conducted

\section{CONCLUSION}

MEPs could be elicited from children aged 13 months when muscles were at rest, and no adverse events following TMS were observed. Age-related changes in MEP latency and amplitude for the FDI, BIC, and DEL muscles indicated that a MEP study may provide insights into maturation of the motor system in healthy children. Based on these results, we suggest that MEP is a useful method to investigate motor developmental disorders in pediatric patients. $^{22}$

\section{ACKNOWLEDGEMENTS}

This research was supported by Basic Science Research Program through the National Research Foundation of Korea (NRF) funded by the Ministry of Education, Science and Technology (2009-0075478).

\section{REFERENCES}

1. Dominkus M, Grisold W, Jelinek V. Transcranial electrical motor evoked potentials as a prognostic indicator for motor recovery in stroke patients. J Neurol Neurosurg Psychiatry 1990; 53: 745-748

2. Sohn YH, Hallett M. Motor evoked potentials. Phys Med Rehabil Clin N Am 2004; 15: 117-131

3. Garvey MA, Mall V. Transcranial magnetic stimulation in children. Clin Neurophysiol 2008; 119: 973-984

4. Lin KL, Pascual-Leone A. Transcranial magnetic stimulation and its applications in children. Chang Gung Med J 2002; 25: 424-436 
5. Nezu A, Kimura S, Uehara S, Kobayashi T, Tanaka M, Saito K. Magnetic stimulation of motor cortex in children: maturity of corticospinal pathway and problem of clinical application. Brain Dev 1997; 19: 176-180

6. Nezu A, Kimura S, Takeshita S. Topographical differences in the developmental profile of central motor conduction time. Clin Neurophysiol 1999; 110: 16461649

7. Curra A, Modugno N, Inghilleri M, Manfredi M, Hallett M, Berardelli A. Transcranial magnetic stimulation techniques in clinical investigation. Neurology 2002; 59: 1851-1859

8. Agnew WF, McCreery DB. Considerations for safety in the use of extracranial stimulation for motor evoked potentials. Neurosurgery 1987; 20: 143-147

9. Sgro JA, Ghatak NR, Stanton PC, Emerson RG, Blair R. Repetitive high magnetic field stimulation: the effect upon rat brain. Electroencephlogr Clin Neurophysiol Suppl 1991; 43: 180-185

10. Counter SA. Neurobiological effects of extensive transcranial electromagnetic stimulation in an animal model. Electroencephalogr Clin Neurophysiol 1993; 89: 341-348

11. Gilbert DL, Garvey MA, Bansal AS, Lipps T, Zhang J, Wasermann EM. Should transcranial magnetic stimulation research in children be considered minimal risk? Clin Neurophysiol 2004; 15: 1730-1739

12. Kirton A, Deveber G, Gunraj C, Chen R. Neurocardiogenic syncope complicating pedriatric transcranial magnetic stimulation. Pediatr Neurol 2008; 39: 196197

13. Müller K, Kass-Iilyya F, Reitz M. Ontogeny of ipsilateral corticospinal projections: a developmental study with transcranial magnetic stimulation. Ann Neurol 1997; 42: 705-711

14. Koh TH, Eyre JA. Maturation of cotricospinal tracts assessed by electromagnetic stimulation of the motor cortex. Arch Dis Child 1988; 63: 1347-1352

15. Wassermann EM. Risk and safety of repetitive transcranial magnetic stimulation: report and suggested guidelines from the International Workshop on the Safety of Repetitive Transcranial Magnetic Stimulation, June 5-7, 1996. Electroencephalogr Clin Neurophysiol 1998; 108: 1-16

16. Roick H, von Giessen HJ, Benecke R. On the origin of the postexcitatory inhibition seen after transcranial magnetic brain stimulation in awake human subjects. Exp Brain Res 1993; 94: 489-498

17. Cantello R, Gianelli M, Civardi C, Mutani R. Magnetic brain stimulation. the silent period after motor evoked potential. Neurology 1992; 42: 1951-1959

18. Garvey MA, Ziemann U, Bartko JJ, Denckla MB, Barker CA, Wassermann EM. Cortical correlates of neuromotor development in healthy children. Clin Neurophysiol 2003; 114: 1662-1670

19. Müller K, Hömberg V, Lenard HG. Magnetic stimulation of motor cortex and nerve roots in children. Maturation of cortico-motoneuronal projections. Electroencephalogr Clin Neurophysiol 1991; 81: 63-70

20. Rothwell JC, Thompson PD, Day BL, Dick JP, Kachi T, Cowan JM, Marsden CD. Motor cortex stimulation in intact man. 1. General characteristics of EMG responses in different muscles. Brain 1987; 110: 11731190

21. Jung HY, Yoon JS, Park BS. Recovery of proximal and distal arm weakness in the ipsilateral upper limb after stroke. NeuroRehabilitation 2002; 17: 153-159

22. Frye RE, Rotenberg A, Ousley M, Pascual-Leone A. Transcranial magnetic stimulation in child neurology: current and future directions. J Child Neurol 2008; 23: 79-96 